\title{
Los particulares frente a la inexistente equidad federal ${ }^{1}$
}

Individuals facing the non-existent federal equity

\author{
Agustina Castro ${ }^{2}$
}

Universidad de Buenos Aires, Argentina

Revista Derechos en Acción ISSN 2525-1678/ e-ISSN 2525-1686

Año 6/Nº 19 Otoño 2021 (21 marzo a 20 junio), 319-337

DOl: https://doi.org/10.24215/25251678e519

Recibido: 03/02/2021

Aprobado: 15/05/2021

\section{Federalismo fiscal}

La reforma constitucional de 1994 buscó, como uno de sus objetivos principales, el fortalecimiento del federalismo. Esto quedó evidenciado en una variedad de artículos que conforman el plexo constitucional reformado.

Siguiendo como referencia al artículo primero de la Constitución Nacional $^{3}(\mathrm{CN})$-que establece que la Nación Argentina acoge la forma federal de Estado como vínculo entre el poder y el territorio-, los arts. 123 y $129^{4}$ introducen dos nuevos actores

\footnotetext{
1 Trabajo elaborado en el marco de la materia "Elementos de Derecho Constitucional", cátedra del Dr. Raúl Gustavo Ferreyra, a cargo del Dr. Mario F. Cámpora, Facultad de Derecho, Universidad de Buenos Aires.

2 Estudiante de Abogacía, Universidad de Buenos Aires, Facultad de Derecho.

3 Art. 1, CN, (1994): "La Nación Argentina adopta para su gobierno la forma representativa republicana federal, según la establece la presente Constitución".

4 Art. 123, CN, (1994): “Cada provincia dicta su propia constitución, conforme a lo dispuesto por el Artículo $5^{\circ}$ asegurando la autonomía municipal y reglando su alcance y contenido en el orden institucional, político, administrativo, económico y financiero".
} 
al sistema ya formado por las provincias y el Estado Nacional, estos son, los municipios y la Ciudad Autónoma de Buenos Aires. Asimismo, en el art. $121^{5}$ reposa la regla fundacional del federalismo argentino, que dispone que las provincias conservan todo el poder no delegado al Estado Nacional.

Además de lo mencionado y como tema central del trabajo, la reforma constitucional del 1994 instaura la necesidad -y la obligación legislativa- de establecer un sistema de coparticipación federal de impuestos en acuerdo entre la Nación y las provincias, es decir, un sistema de distribución automática de fondos públicos en función de diversas pautas objetivas constitucionales en virtud del art. 75 inc. 2 de la $\mathrm{CN}^{6}$. La norma constitucional dispone que, para la sanción de la ley convenio o de coparticipación federal, se deberán contemplar criterios objetivos de reparto; la ley deberá velar por la equidad, solidaridad y dará prioridad al logro de un grado equivalente de desarrollo, calidad de vida e igualdad de oportunidades (Const., 1994, art. 75 inc. 2). En adición a las pautas que instaura el artículo mencionado y en relación al mismo, se podría introducir el art. 75 inc. $19^{7}$ en cuanto implanta el deber legislativo

Art. 129, CN, (1994): "La Ciudad de Buenos Aires tendrá un régimen de gobierno autónomo con facultades propias de legislación y jurisdicción, y su jefe de gobierno será elegido directamente por el pueblo de la ciudad...".

5 Art. 121, CN, (1994): "Las provincias conservan todo el poder no delegado por esta Constitución al Gobierno federal, y el que expresamente se hayan reservado por pactos especiales al tiempo de su incorporación".

6 Art. 75 inc. 2, CN, (1994): “. .. Una ley convenio, sobre la base de acuerdos entre la Nación y las provincias, instituirá regímenes de coparticipación de estas contribuciones, garantizando la automaticidad en la remisión de los fondos. La distribución entre la Nación, las provincias y la ciudad de Buenos Aires y entre éstas, se efectuará en relación directa a las competencias, servicios y funciones de cada una de ellas contemplando criterios objetivos de reparto; será equitativa, solidaria y dará prioridad al logro de un grado equivalente de desarrollo, calidad de vida e igualdad de oportunidades en todo el territorio nacional. La ley convenio tendrá como Cámara de origen el Senado y deberá ser sancionada con la mayoría absoluta de la totalidad de los miembros de cada Cámara, no podrá ser modificada unilateralmente ni reglamentada y será aprobada por las provincias...".

7 Art. 75 inc. 19, CN, (1994): "Proveer lo conducente al desarrollo humano, al progreso económico con justicia social, a la productividad de la economía nacional, a la generación de 
de promover el desarrollo humano y el progreso económico con justicia social; y el art. 75 inc. $18^{8}$ que de manera similar, dispone que el Congreso además deberá gestionar su actividad de forma tal que conduzca a la prosperidad del país, al adelanto y bienestar de todas las provincias.

Siguiendo la imperiosa necesidad de establecer un sistema automático de remisión de fondos públicos, la disposición sexta de la $\mathrm{CN}^{9}$ establece un límite temporal para la sanción de la ley convenio que dispone el art. 75 inc. 2; este es, antes de la finalización del año 1996. La ley convenio al año 2020, sigue sin ser sancionada por no contar con los consensos políticos suficientes para "operativizar" la Constitución. Como consecuencia de esto, los ciudadanos, los gobiernos provinciales e incluso los municipales del país se ven afectados de innumerables maneras.

empleo, a la formación profesional de los trabajadores, a la defensa del valor de la moneda, a la investigación y al desarrollo científico y tecnológico, su difusión y aprovechamiento. Proveer al crecimiento armónico de la Nación y al poblamiento de su territorio; promover políticas diferenciadas que tiendan a equilibrar el desigual desarrollo relativo de provincias y regiones. Para estas iniciativas, el Senado será Cámara de origen. Sancionar leyes de organización y de base de la educación que consoliden la unidad nacional respetando las particularidades provinciales y locales; que aseguren la responsabilidad indelegable del Estado, la participación de la familia y la sociedad, la promoción de los valores democráticos y la igualdad de oportunidades y posibilidades sin discriminación alguna; y que garanticen los principios de gratuidad y equidad de la educación pública estatal y la autonomía y autarquía de las universidades nacionales...".

8 Art. 75 inc. 18, CN, (1994): "Proveer lo conducente a la prosperidad del país, al adelanto y bienestar de todas las provincias, y al progreso de la ilustración, dictando planes de instrucción general y universitaria , y promoviendo la industria, la inmigración, la construcción de ferrocarriles y canales navegables, la colonización de tierras de propiedad nacional, la introducción y establecimiento de nuevas industrias, la importación de capitales extranjeros y la exploración de los ríos interiores, por leyes protectoras de estos fines y por concesiones temporales de privilegios y recompensas de estímulo".

9 Disposición sexta, CN, (1994): “Un régimen de coparticipación conforme lo dispuesto en el inc. 2 del Artículo 75 y la reglamentación del organismo fiscal federal, serán establecidas antes de la finalización del año 1996; la distribución de competencias, servicios y funciones vigentes a la sanción de esta reforma, no podrá modificarse sin la aprobación de la provincia interesada; tampoco podrá modificarse en desmedro de las provincias la distribución de recursos vigente a la sanción de esta reforma y en ambos casos hasta el dictado del mencionado régimen de coparticipación...". 
En base a lo expuesto y en relación a las normas mencionadas, se está frente a una inconstitucionalidad por omisión ${ }^{10}$ en cuanto el Poder Legislativo Nacional no ha logrado el dictado de la ley de coparticipación exigida por el art. 75 inc. 2 y disposición sexta de la CN. Como efecto directo, no se cumplen los mandatos constitucionales relacionados a la equidad, solidaridad y desarrollo equivalente propio de un sistema federal. La ley convenio es, hasta el día de hoy, una promesa incumplida de la reforma constitucional de 1994.

A causa de la omisión legislativa en dictar la ley de coparticipación federal de impuestos que manda la $\mathrm{CN}$, nos debemos referir a una ley anterior para discutir la distribución de recursos fiscales. La ley 23.548sobre distribución de fondos-utilizada actualmente- fue sancionada y promulgada en 1988, es decir, previa a la reforma constitucional de 1994 , por lo tanto, no es la ley a la que la $\mathrm{CN}$ reformada hace referencia.

El federalismo, como he aludido anteriormente, implica ideas de solidaridad y equidad, es decir, buscar la manera más adecuada de generar y perseguir objetivos de igualdad de oportunidades en todo el país. El mismo art. 75 inc. 2 hace mención a esto, y en este sentido, establece pautas objetivas de equidad siguiendo los principios del federalismo y el desarrollo equivalente. A pesar de esto, al observar la ley 23.548 y más específicamente su art. 4, se puede apreciar que se le atribuye, a cada provincia, porcentajes de aplicación para la remisión de fondos públicos. Como ejemplo, cito a la provincia de Buenos Aires, a la cual se le imputa un $19,93 \%$ de los fondos coparticipables. Esto acarrea diversos problemas. Existe una incompatibilidad entre los mandatos constitucionales -en cuanto a la equidad y solidaridad federal-y la ley 23.548 sobre distribución de recursos fiscales.

\footnotetext{
10 "Inconstitucionalidad por omisión" en los términos del art. 43 de la CN (1994), referido a la presentación de un recurso de amparo por omisión de autoridades públicas o particulares cuando se haya lesionado, restringido, alterado o amenazado un derecho reconocido en la $\mathrm{CN}$, tratado internacional o una ley. En adición, BIDART CAMPOS, Germán, (2006). Capítulo XXVI "Amparo", punto 20 en Manual de la constitución reformada, Sociedad Anónima Editora, Buenos Aires.
} 
Como se advierte, la imposición de porcentajes a las provincias para la remisión de fondos, no cumple en absoluto con el esquema y mandato constitucional al no seguir criterios objetivos de reparto teniendo en vista, además, la idea de equidad federal. Esto significa que, en lugar de reparar en las condiciones de cada provincia y repartir los fondos en virtud de esto, la ley 23.548 únicamente establece porcentajes a las provincias que no son más que la fuerza de cada gobernador en asegurarse cierta cantidad de capital en 1988. No existe en esta norma de distribución de fondos públicos una objetivación de la equidad.

Esta forma de distribución de los fondos coparticipables no solo no persigue los mandatos constitucionales, sino que, además, son pasibles de devaluación a través del tiempo. No es difícil imaginar que con el transcurso del tiempo las provincias puedan mejorar su situación o, por el contrario, empeorarla y, por lo tanto, necesitar obtener aún más recursos fiscales para satisfacer sus necesidades y así cumplir con el federalismo como instrumento de solidaridad y equidad. Si los porcentajes previstos en la ley 23.548 se mantienen sin actualizar durante largos períodos, no solo no se cumple con los preceptos constitucionales sobre equidad y solidaridad, sino que no habilita el progreso provincial por un estancamiento producido por la misma ley.

En adición a lo desarrollado, al ser la ley 23.548 anterior a la reforma constitucional de 1994, la Ciudad Autónoma de Buenos Aires y la provincia de Tierra del Fuego no estaban constituidas aún como tal y la remisión de fondos en estos territorios actualmente se lleva a cabo no con fondos coparticipables, sino con fondos nacionales mediante decretos presidenciales en virtud del art. 8 de la misma ley. Como consecuencia de lo dicho, la idea de consenso -entre provincias y el Estado Nacional- prevista en la Constitución haciendo referencia a la ley convenio para la distribución de recursos, se ve ampliamente trasgredida. De esta forma, la atribución de fondos en los territorios mencionados, 
muchas veces pueden ser materia de arbitrariedad o discrecionalidad ya que se le confiere un amplio margen de maniobra a la figura presidencial en estos territorios.

\section{Doctrina jurisprudencial}

Luego de la incorporación constitucional de la necesidad de un sistema automático de remisión de fondos, las provincias en sus constituciones replicaron ese sistema para crear la misma automaticidad en ámbito municipal. La Corte Suprema de Justicia de la Nación (CSJN) en su fallo "Intendente de la Rioja"11, dirime sobre los conflictos que trae aparejada la ausencia de ley de coparticipación de impuestos en la provincia de La Rioja. El demandante al interponer un recurso de amparo, alega que, a raíz de esto, los municipios riojanos se encuentran sujetos a la discrecionalidad del gobierno provincial a la hora de repartir los fondos afectando así, la autonomía municipal que impone la CN como regla del federalismo. La CSJN concluye en que existe una pauta irracional en la tardanza en dictar una ley de coparticipación provincial. Es irrazonable pensar que, en 16 años, la legislatura provincial no logró generar los consensos suficientes para sancionar la ley y, por lo tanto, "operativizar" la Constitución Nacional.

Siguiendo las ideas del caso anterior, la Corte Suprema de Justicia de la Nación en su fallo "Bazán"12 al discutir sobre la autonomía jurisdiccional en CABA, evalúa el federalismo en la Argentina. Se encarga de analizar los perjuicios que ocasiona no respetar la idea del federalismo y los mandatos constitucionales. En su considerando décimo la Corte, haciendo referencia al fallo mencionado en el párrafo anterior, analiza también la irrazonabilidad en el tiempo transcurrido en el que el traspaso

\footnotetext{
11 Corte Suprema de Justicia de la Nación, fallo 337:1263, 2014, “Intendente municipal capital s/amparo".

12 Corte Suprema de Justicia de la Nación, fallo 342:509, 2019, “Bazán, Fernando s/amenazas".
} 
de justicia no se llevó a cabo en CABA, vulnerando así, el federalismo y la autonomía porteña. La Corte advierte en su fallo que las omisiones legislativas impactan directamente con las reglas básicas del federalismo en Argentina en tanto los constituyentes procuraron fortalecer el federalismo en la reforma de 1994.

Dada la gravedad que reviste la omisión legislativa en dictar la ley en cuestión (Const., 1994 art. 75 inc. 2) es de utilidad referirse al fallo "Badaro c/ ANSeS"13 para lograr comprender que el Poder Judicial, en ciertas ocasiones o casos en particular, se ha visto en la posición de exhortar a los demás poderes del Estado a cumplir con sus funciones y por ende, sus obligaciones. Si bien las cuestiones referidas a omisiones de autoridades públicas implican sostener el principio republicano en tanto los poderes del Estado no deben sobrepasar sus atribuciones, la CSJN en el fallo mencionado, analizando la movilidad de las pensiones (Const., 1994 art. 14 bis) y el deber legislativo en sancionar su reglamentación ${ }^{14}$, dictamina respecto a la importancia de la obligación del Congreso en ejecutar sus funciones y la gravedad de su omisión en realizarlas. Por esta razón, en su considerando $24^{015}$, la CSJN incita al Poder Legislativo a sancionar la reglamentación de la movilidad de pensiones, es decir, cumplir con su obligación constitucional. En conclusión, en las cuestiones relativas a omisiones legislativas, el Poder Judicial

\footnotetext{
13 Corte Suprema de Justicia de la Nación, fallo 330:4866, 2007, "Badaro, Adolfo Valentín c/ ANSeS s/ reajustes varios"

14 Art. 75 inc. 32, CN, (1994): Hacer todas las leyes y reglamentos que sean convenientes para poner en ejercicio los poderes antecedentes, y todos los otros concedidos por la presente Constitución al Gobierno de la Nación Argentina.
}

15 Corte Suprema de Justicia de la Nación, fallo 330:4866, considerando 24: “Que, en este entendimiento, esta Corte considera que contribuiría a dar mayor seguridad jurídica el dictado de una ley que estableciera pautas de aplicación permanentes que aseguren el objetivo constitucional. Una reglamentación prudente de la garantía en cuestión, además de facilitar el debate anual sobre la distribución de recursos y evitar el uso de facultades discrecionales, permitiría reducir la litigiosidad en esta materia, que ha redundado en menoscabo de los derechos de los justiciables y del adecuado funcionamiento del Poder Judicial (Fallos: 328:566 "Itzcovich"), por lo que se formula una nueva exhortación a las autoridades responsables a fin de que examinen esta problemática". 
debe mediar entre el principio republicano y la protección a los derechos fundamentales y así, con estas consideraciones, favorecer al otorgamiento de derechos y reclamar el cumplimiento de deberes a los poderes del Estado sin trasgredir los principios de gobierno.

Esto sirve para comprender que, si bien es cierto que el Poder Judicial dicta resoluciones particulares, es decir, no emite normativa general por ser esta atribución del Congreso Nacional, un caso individual puede extender sus efectos al resto de la población. De esta forma, por ejemplo, luego del pronunciamiento por parte de la CSJN en el caso "Intendente de la Rioja", la ley de coparticipación provincial fue sancionada y los demás municipios se vieron favorecidos en cuanto se pudo distribuir los fondos públicos de acuerdo a la Constitución provincial dejando de lado las arbitrariedades y discrecionalidades por parte del gobierno. En otras palabras, los dictámenes de la CSJN tienen la fuerza suficiente para lograr que los demás poderes del Estado pongan en funcionamiento sus atribuciones impuestas por la $\mathrm{CN}$ y así favorecer no solo al demandante sino al resto del país.

A raíz de lo relatado, se revela la posibilidad de imaginar una forma en la que un particular pueda demandar una lesión concreta, resultante de la faltante ley de coparticipación federal que la $\mathrm{CN}$ impone sancionar, y así extender los efectos de la sentencia a todo el país, es decir, que la CSJN -preferentementeincite al Poder Legislativo a cumplir con su deber instaurado en el art. 75 inc. 2.

\section{El amparo como creación pretoriana y mecanismo para garantizar derechos constitucionales}

La Constitución histórica, más allá de todos los aspectos negativos que se le pueden imputar, hay uno que sobresale de los demás. Esta es, la omisión, por parte de la constituyente, de establecer efectivamente un mecanismo o procedimiento de 
garantía constitucional. La Constitución de 1853 no contiene en su plexo normativo ningún tipo de régimen que le permitiese a los ciudadanos garantizar, proteger o exigir sus derechos constitucionales. Ahora cabría preguntarse si es posible imaginar la existencia de derechos sustanciales -previos- sin considerar un mecanismo idóneo $\mathrm{y}$, por lo tanto, efectivo para reclamarlos $\mathrm{y}$ hacerlos valer, en otras palabras, un derecho procesal constitucional. Antes de la reforma, ¿Cómo se exigían los derechos constitucionales si no existían las herramientas para protegerlos de violaciones por parte de otro sujeto?

Esta situación revela un problema concreto. Para que los derechos enunciados por la $\mathrm{CN}$ no se transformen en meras declaraciones, se necesitan otorgar garantías que los protejan, amparen y hagan valer ante actuales o posibles vulneraciones. En la medida en que el afectado no pueda iniciar una acción para proteger sus derechos constitucionales de otros sujetos que los vulneran, la $\mathrm{CN}$ pierde su sentido en cuanto otorgante de derechos fundamentales. Es irónico pensar que, la carta fundamental, el conjunto de normas que le otorga sentido a todas las demás ramas del derecho, no contenga ningún sistema efectivo que la proteja.

Por lo mencionado, dada la faltante garantía constitucional, fue iniciativa del poder judicial el crear un medio por el cual los ciudadanos puedan reclamar sus derechos fundamentales. A partir de los históricos fallos "Siri"16 y "Kot"17 la CSJN deja sentado un procedimiento de recurso efectivo. Por esta razón el amparo es considerado creación pretoriana, es decir, creada por los pretores o jueces. Años más tarde, en 1966, durante la última dictadura militar, fue sancionada la ley de amparo -16.986- que aún el día de hoy es utilizada en la materia.

\footnotetext{
16 Corte Suprema de Justicia de la Nación, fallo 239:459, 1957, “Siri, Samuel S., s/interpone recurso de hábeas corpus".

17 Corte Suprema de Justicia de la Nación, fallo 241:291, 1958, “Kot, Samuel S.R.L., s/recurso de hábeas corpus".
} 
Con la reforma constitucional de 1994 es introducida la figura del amparo al aparato constitucional. El art. $43^{18}$ de la actual $\mathrm{CN}$, replica ampliamente las reglas que establece la ley 16.986 en cuanto a la conceptualización del amparo como garantía constitucional $^{19}$. Según indica el artículo mencionado, el amparo se erige como una acción expedita y rápida; para interponerlo, deberá ser el medio más idóneo de reclamo; y puede ser interpuesto ante actos u omisiones de autoridades públicas o particulares donde exista una vulneración o lesión actual o inminente a derechos constitucionales, derechos establecidos en tratados internacionales o leyes. Asimismo, el artículo dispone que los jueces, en el caso concreto, podrán declarar la inconstitucionalidad de la norma en la que se funda el acto u omisión.

En adición, la Declaración Universal de Derechos Humanos, que luego de 1994 cuenta con jerarquía constitucional en virtud del artículo 75 inc. 22, dispone en su artículo octavo ${ }^{20}$ el derecho de toda persona a un recurso efectivo con el fin de proteger sus derechos constitucionales o establecidos en una ley.

\footnotetext{
18 Art. 43, CN, (1994): “Toda persona puede interponer acción expedita y rápida de amparo, siempre que no exista otro medio judicial más idóneo, contra todo acto u omisión de autoridades públicas o de particulares, que en forma actual o inminente lesiones, restrinja, altere 0 amenace, con arbitrariedad o ilegalidad manifiesta, derechos y garantías reconocidos por esta Constitución, un tratado o una ley. En el caso, el juez podrá declarar la inconstitucionalidad de la norma en que se funde el acto u omisión lesiva. Podrán interponer esta acción contra cualquier forma de discriminación y en lo relativo a los derechos que protegen al ambiente, a la competencia, al usuario y al consumidor, así como a los derechos de incidencia colectiva en general, el afectado, el defensor del pueblo y las asociaciones que propendan a esos fines, registradas conforme a la ley, la que determinará los requisitos y formas de su organización...".

19 El artículo primero de la ley de amparo 16.986, de manera casi idéntica al artículo 43 de la CN, dispone: "La acción de amparo será admisible contra todo acto u omisión de autoridad pública que, en forma actual o inminente, lesione, restrinja, altere o amenace, con arbitrariedad o ilegalidad manifiesta, los derechos o garantías explícita o implícitamente reconocidos por la Constitución Nacional, con excepción de la libertad individual tutelada por el hábeas corpus".
}

20 Art. 8, Declaración Universal de Derechos Humanos: "Toda persona tiene derecho a un recurso efectivo, ante los tribunales nacionales competentes, que la ampare contra actos que violen sus derechos fundamentales reconocidos por la Constitución o por la ley". 


\section{Amparo para exigir normas de organización del poder}

En el fallo "intendente de La Rioja", el demandante interpuso una acción de amparo para lograr la sanción de la ley de coparticipación provincial que exigía la constitución riojana, afirmar la autonomía municipal y acabar con las discrecionalidades y arbitrariedades en el reparto de los fondos provinciales. Es decir, el demandante interpuso acción de amparo ante la omisión legislativa en dictar la ley de coparticipación provincial establecida en la constitución riojana a fin de que se declare su inconstitucionalidad. Como respuesta, el Tribunal Superior de Justicia de la provincia rechazó el pedido por varias razones; esto es, porque no es facultad del poder judicial dictar normativa general, en este caso el sistema de coparticipación -por principio republicano-; porque la materia significa una cuestión política no justiciable y; porque el sistema de coparticipación debe ser edificado sobre la base de acuerdos entre la provincia y los municipios, y estos no habían sido concretados aún.

Ante esta problemática, la CSJN dispuso que, si bien son acertadas las interpretaciones de los jueces del Tribunal Superior de Justicia de La Rioja, lo cierto es que existe una irrazonabilidad en el tiempo transcurrido sin haber generado los consensos y acuerdos políticos para sancionar la ley de coparticipación provincial $^{21}$. De esta forma, la Corte deja sin efecto la resolución del tribunal anterior y da procedencia al recurso interpuesto.

21 En el fallo citado, $(337: 1263,2014)$, la CSJN en análisis de la problemática dispuso en su considerando 11: "Es incuestionable que la omisión del dictado de la ley que coparticipa fondos entre los municipios lesiona el diseño mismo establecido por el constituyente, y que por esa vía la provincia traspone los límites de los racional y razonable para la vigencia efectiva de la autonomía municipal”. La CSJN consideró además, en su considerando $13^{\circ}$ que, " ... no resulta posible sostener que el dictado de la ley -es decir, el acatamiento de la Constitución queda condicionado a la concreción de acuerdos políticos entre provincia y municipios que en 16 años no han sido logrados. Al subordinar la realización del proyecto constitucional a la posibilidad o no de obtener esos acuerdos sin considerar la irrazonable demora en alcanzarlos, el argumento invierte una regla elemental de orden constitucional argentino, según el cual la Constitución materializa el consenso más perfecto de la soberanía popular; frente a sus definiciones, los poderes constituidos deben realizar todos los 
Cabe preguntarse si efectivamente el amparo puede ser interpuesto ante las omisiones legislativas y en este caso en concreto, ante la omisión en dictar la ley de coparticipación federal de impuestos que indica el art. 75 inc. 2 de la CN. Como objetivo principal de este trabajo, trataré de despejar toda duda a esta problemática para lograr entender si realmente un particular puede interponer un amparo como garantía constitucional ante la omisión por parte del Poder Legislativo en dictar leyes, y más específicamente, la ley de coparticipación federal de impuestos. Para esto, realizaré un desglose del primer párrafo del artículo 43 de la $\mathrm{CN}$ con la intención de analizar cada punto o carácter en particular y resolviendo la cuestión en base a un caso hipotético como referencia.

\section{Necesidades básicas insatisfechas como consecuencia de la omisión legislativa}

"A" vive en Santiago del Estero. Las condiciones de vida, la infraestructura y viviendas en la localidad son precarias y "A" no logra satisfacer sus necesidades básicas. La infraestructura hospitalaria y escolar es precaria, existe una gran faltante de recursos y muchas veces los niños han visto la necesidad de tener que ausentarse a clases por estas razones. Asimismo, no hubo instalaciones de cloacas ni existe acceso a agua potable.

"A" decide realizar un reclamo en el municipio de su localidad, pero estos se vieron imposibilitados a mejorar la situación ya que dicen no tener los recursos fiscales necesarios para satisfacer las necesidades de los habitantes. Ante esta respuesta, "A" concurre al gobierno provincial con el objetivo de obtener una respuesta. Sin embargo, el gobierno provincial, de manera similar al municipal, explica que, ante la omisión de reparto equitativo de fondos públicos, Santiago del Estero no obtiene 
los recursos que debería no pudiendo satisfacer las necesidades de sus habitantes.

Cabe analizar si "A" se encuentra facultado para interponer un amparo por omisión legislativa en sancionar la ley de coparticipación federal a fin de que el juez a cargo declare la inconstitucionalidad de la misma.

Art. 43: "Toda persona puede interponer acción expedita y rápida de amparo, siempre que no exista otro medio judicial más idóneo...".

Al presentar un amparo, es necesario que el recurso sea el medio más idóneo para llevar a cabo el reclamo. Es decir, como he explicado anteriormente y posteriormente también haré referencia, el amparo es un medio que procede ante la lesión a un derecho constitucional, un derecho consagrado en un tratado internacional o una ley. Es un mecanismo propio para reclamar la vulneración a derechos exclusivamente mencionados en el art. 43 de la CN. Siguiendo esta línea, sería difícil imaginar que una cuestión de derecho civil, como puede ser una compra venta, se resuelva por un medio distinto al procesal civil. De esta manera, la lesión de un derecho constitucional, en virtud del art. 43 de la $\mathrm{CN}$, se resuelve a través de la presentación de un amparo como medio idóneo en la materia.

En base al caso, la ley utilizada actualmente para la remisión de fondos públicos, como he explicado, establece porcentajes a las provincias para la tarea. De esta manera, los criterios objetivos de reparto que manda la constitución a respetar para garantizar mejores condiciones de vida para la población argentina no son considerados de ninguna forma. Es decir, la ley 23.548 no contempla las necesidades básicas insatisfechas, la falta de cloacas, la precaria infraestructura escolar y hospitalaria, etc., ergo, es imaginable pensar que los habitantes de ciertas localidades del país encuentren insatisfechas necesidades consideradas básicas en tanto derechos humanos.

En cuanto a la presentación de un amparo por omisión legislativa en dictar la ley de coparticipación federal, en un 
principio se funda en el incumplimiento por parte del Congreso Nacional en dictar la ley convenio que establece el art. 75 inc. 2 como facultad exclusiva del Poder Legislativo. En el supuesto expuesto como caso hipotético, el artículo 14 de la $\mathrm{CN}^{22}$ es lesionado de manera directa en cuanto el derecho a la enseñanza o educación como tal -de manera adecuada, en condiciones propias de un ambiente escolar-, como también la igualdad de oportunidades esgrimida en la misma Constitución en su artículo $16^{23}$. En tanto derechos consagrados en tratados internacionales, el derecho al agua ${ }^{24}$ se encuentra vulnerado, al igual que el derecho a la salud ${ }^{25}$ (Declaración Universal de Derechos Humanos). En relación a la falta de cloacas en la localidad, el art. 41(CN, 1994) consagra el derecho al ambiente sano y limpio a todos los habitantes de la Nación.

Existe una variedad amplia de artículos constitucionales y tratados internacionales que subrayan la idea de que el incumplimiento en sancionar la ley básica del federalismo, apareja consecuencias enormes para la población. De todas formas, el objetivo del trabajo no es exponer la normativa relacionada,

22 Art. 14, CN, (1994): “Todos los habitantes de la Nación gozan de los siguientes derechos conforme a las leyes que reglamenten su ejercicio; a saber: de trabajar y ejercer toda industria lícita; de navegar y comerciar; de peticionar a las autoridades; de entrar, permanecer, transitar y salir del territorio argentino; de publicar sus ideas por la prensa sin censura previa; de usar y disponer de su propiedad; de asociarse con fines útiles; de profesar libremente su culto; de enseñar y aprender".

23 Art. 16, CN, (1994): "La Nación Argentina no admite prerrogativas de sangre, ni de nacimiento: no hay en ella fueros personales ni títulos de nobleza. Todos sus habitantes son iguales ante la ley, y admisibles en los empleos sin otra condición que la idoneidad. La igualdad es la base del impuesto y de las cargas públicas".

24 En el año 2010, la Asamblea General de las Naciones Unidas a través de la Resolución 64/292 reconoció explícitamente el derecho humano al agua.

25 Art. 25, Declaración Universal de Derechos Humanos: “Toda persona tiene derecho a un nivel de vida adecuado que le asegure, así como a su familia, la salud y el bienestar, y en especial la alimentación, el vestido, la vivienda, la asistencia médica y los servicios sociales necesarios; tiene asimismo derecho a los seguros en caso de desempleo, enfermedad, invalidez, viudez, vejez u otros casos de pérdida de sus medios de subsistencia por circunstancias independientes de su voluntad". 
sino analizar la procedencia del amparo como mecanismo de reclamo ante la problemática.

En base a lo expuesto y en análisis de este primer apartado del artículo 43 de la $\mathrm{CN}$, el amparo por omisión de autoridades públicas es procedente en cuanto infringe directamente derechos constitucionales y derechos establecidos en tratados internacionales. Asimismo, la omisión legislativa y la lesión a este tipo de derechos perturba indirectamente a la idea del constitucionalismo social que impera en nuestra Carta Magna luego de la reforma constitucional de 1994.

En adición, cabe mencionar que el proceso del amparo deberá ser rápido y expedito -como lo establece la $\mathrm{CN}$-dada la gravedad que engloba la afectación a un derecho constitucional.

Art. 43: "Contra todo acto u omisión de autoridades públicas o de particulares...".

Este punto en particular resulta evidente. El art. 75 inc. 2 de la CN dispone que se deberá sancionar una ley convenio en base a acuerdos entre la Nación y las provincias, teniendo en cuenta pautas objetivas de reparto. De conformidad con esta norma, la disposición transitoria sexta establece que la ley convenio deberá ser sancionada antes de la finalización del año 1996. Hasta el día de hoy, no se han generado los consensos políticos suficientes para sancionar la ley en discusión. Por el contrario, se utiliza actualmente una ley anterior que como he desarrollado, no cumple con las pautas que impone la CN.

Siguiendo la línea doctrinaria de Bidart Campos, la ley de coparticipación federal no puede ser considerada como "opcional" sino más bien obligatoria ${ }^{26}$. No existen opciones, la ley convenio "deberá ser sancionada" según la CN. En otras palabras, el mandato constitucional no está condicionado a la voluntad de los legisladores.

26 BIDART CAMPOS, Germán, (2006). "La tributación y el poder tributario", Capítulo XIX, punto 43, en Manual de la Constitución Reformada. Ediar, Buenos Aires. 
Conforme a lo expuesto, la faltante ley de coparticipación federal de impuestos puede ser considerada como un supuesto de inconstitucionalidad por omisión por parte del Poder Legislativo de la Nación -autoridad pública- en tanto no ha sido sancionada luego de la reforma constitucional de 1994.

Art. 43; "Que en forma actual o inminente lesione, restrinja, altere o amenace, con arbitrariedad o ilegalidad manifiesta, derechos y garantías reconocidos por esta Constitución, un tratado o una ley. En el caso, el juez podrá declarar la inconstitucionalidad de la norma en que se funde el acto u omisión lesiva."

Para la procedencia de un amparo es necesario acreditar, por parte del demandante, la existencia de una lesión actual o inminente a derechos constitucionales, derechos consagrados en tratados internacionales o derechos dispuestos en la ley. Para esto y en este caso en particular, se deberá probar la relación que existe entre el daño ocasionado y la omisión legislativa.

Suponiendo que una persona que encuentra sus necesidades básicas insatisfechas y desea presentar un amparo por omisión en base a esto alegando que la faltante ley de coparticipación federal -que debe seguir aspectos objetivos de reparto por regla constitucional- afecta directamente la remisión de fondos y, por ende, ve lesionado sus derechos constitucionales, deberá probar este nexo causal que existe entre el daño sufrido y la omisión legislativa.

La situación se complejiza cuando el artículo expone que la arbitrariedad o ilegalidad que lesiona al sujeto demandante deberá ser "manifiesta". Al ser el amparo una vía de reclamo rápida y expedita, el margen para el análisis de la prueba en cuestión es acotado y por esta razón, la afectación deberá ser evidente o manifiesta. Asimismo, al ser una vía rápida y expedita, el reclamo debe acarrear peligro en la demora o transcurso del tiempo.

Si bien es acertado suponer que existe dificultad en establecer el nexo causal "manifiesto" en este caso en concreto y la ley de coparticipación que manda a sancionar la $\mathrm{CN}$ no existe, 
es decir, no se puede asegurar que la sanción de una ley de coparticipación dará efectivamente solución a la problemática, lo cierto es que, si la ley convenio se sanciona en base a las pautas que la $\mathrm{CN}$ impone para llevar a cabo la tarea, la solución llevará a mejores resultados que la situación actual. Si la ley convenio es sancionada en base a las pautas objetivas de reparto que establece el art. 75 inc. 2, esto es, teniendo en cuenta, por ejemplo, las necesidades básicas insatisfechas de los habitantes argentinos, los resultados serán ampliamente superiores en contraposición a la situación actual-ley 23.548- en tanto asegurará una forma equitativa y solidaria de reparto, en correlato, además, con los principios federales que dispone la CN. La correcta remisión de fondos públicos, teniendo en cuenta parámetros objetivos de reparto, garantizará mayor equidad entre los habitantes argentinos.

En cuanto al nexo causal que deberá probar el demandante, considero suficiente demostrar que, al realizar el reclamo ante las autoridades, obtuvo una respuesta negativa por partes de estas por no contar con recursos suficientes para distribuir y lograr mayores niveles de equidad entre la población. En vista de la omisión legislativa en dictar la ley de coparticipación que manda la $\mathrm{CN}$ e cumpliendo con los parámetros objetivos que la misma impone, la provincia no cuenta con recursos suficientes para cubrir las necesidades básicas de la población.

La CN busca, a través de una variedad de artículos ya mencionados, generar mayores niveles de equidad entre la ciudadanía y mejores condiciones de vida. Es correcto afirmar que la inadecuada distribución de fondos profundiza ampliamente la desigualdad en el país, avasallando de esta manera, la idea de solidaridad federal que impera en el texto constitucional desde 1994. El precario sistema de salud, la inadecuada infraestructura escolar, y las pésimas condiciones de vida relatados en el caso, son consecuencia directa de la falta de reparto equitativo de los fondos públicos. Que la provincia de Santiago del Estero, -en este caso- no logre satisfacer las necesidades básicas de sus 
habitantes es el resultado de la omisión legislativa en dictar la norma que le fue impuesta para regular la distribución de fondos en el país. No es posible imaginar que, sin un reparto equitativo, todos los habitantes del país hallen sus necesidades satisfechas, precisamente, por no contar con los recursos suficientes. Una mala distribución significa privilegios para algunos, desventajas para otras.

\section{Consideraciones finales}

Si bien es cierto que con la reforma constitucional de 1994 se buscó fortalecer el federalismo, queda evidenciado que la realidad política no se adecúa -o no quiere adecuarse- al precepto.

En este sentido, y siguiendo esta línea de análisis, se puede mencionar como referencia que la Constitución de 1853, influenciada por ideas alberdianas, fue un gran acierto político pragmático en tanto buscó ser realista respecto a la vida política de la época para así plasmarlo en el texto constitucional ${ }^{27}$. Por el contrario, cabría preguntarse si la lectura política, económica y social realizada en 1994 en el marco de la reforma constitucional, -con el claro objetivo de fortalecer el federalismo- realmente se identifica con los valores que realcen este tiempo y espacio. Desde una perspectiva analítica, tal vez la reforma no fue un

27 FERREYRA, Raúl Gustavo, (2015). Fundamentos constitucionales, Lección segunda, "1852. Orígenes. Sobre las bases de Juan Bautista Alberdi y la Constitución federal, en el tiempo", Ediar, Buenos Aires, p. 12. Cito los fragmentos de mayor relevancia: "Una constitución coherente no es solamente un código en el que el contenido de sus normas no es contradictorio; se trata, principalmente, de un texto normativo que prescribe un campo de acción ideal proyectado hacia la realidad comunitaria. Cuando un poder constituyente produce una constitución quiere, desea 0 ambiciona que la realidad comunitaria tenga identidad o guarde semejanza con el ámbito de lo prescripto. Por intermedio de las normas constitucionales se establece con eminente fuerza prescriptiva el estado de cosas diseñado por el propio legislador constituyente u originario, ya sea por normas de conducta y/o normas de competencia"; "La historia de un pueblo o la evolución de la autodeterminación o soberanía comunitaria puede ser descubierta en cada proyecto de constitución. Una constitución 0 un proyecto delimita un tiempo constituyente. Además, cada constitución, señaladamente, responde a determinada ideología o valoración política, posee una estructura específica y observa determinadas finalidades". 
proyecto aceptable políticamente en este contexto. Más bien, la reforma significó una observación errónea o equivocada de la realidad en 1994. En otras palabras, la sociedad argentina no estaba lista para afianzar el federalismo.

Parece ser que el federalismo en la Argentina es una gran cuenta pendiente de la última reforma constitucional. Esta idea se verifica al evaluar, como lo hizo la CSJN, la irrazonabilidad en el tiempo transcurrido sin que el Poder Legislativo genere los consensos políticos necesarios para la sanción de la ley convenio como atribución exclusiva del mismo, siendo esta la base de un sistema federal. Mientras las reglas básicas de la Constitución y más específicamente del federalismo no sean implementadas, no será posible imaginar un progreso nacional con justicia social en la Argentina. El Estado ha fallado en su deber de generar y garantizar igualdad en el país causando así, malestar en su propio organismo ${ }^{28}$. De esta forma, considero hipócrita las acciones políticas tendientes a "discutir" la erradicación de la pobreza y el progreso económico cuando las reglas constitucionales básicas que proponen y efectivizan mayores niveles de equidad, no se ejecutan. Por este motivo es de suma importancia insistir en el cumplimiento de los mandatos constitucionales que procuran el progreso social y el bienestar general ${ }^{29}$. La reforma constitucional nos introduce la garantía del amparo y con ello la posibilidad de reclamar esta gran faltante. Como particulares y como destinatarios de los derechos constitucionales, debemos asegurarnos de promover acciones que logren incitar al aparato estatal a cumplir con las obligaciones que impone la CN.

28 FERREYRA, Raúl Gustavo, (2020). Malestar en el Estado. Ediar, Buenos Aires, p. 15. El autor introduce la idea de que ninguna constitución fomenta o promueve el malestar. Sin embargo, a pesar de esto y a la luz del estudio "Gobernar es igualar", interpreta al malestar en el Estado como consecuencia de la desigualdad en el territorio. De esta forma, se justifica al Estado a partir de su deficiencia a la hora de promover y efectivizar igualdad.

29 El Preámbulo de la CN establece como objetivo de la unión nacional, el promover el bienestar general. 